\title{
Mapping the Aggregation Kinetics of a Therapeutic Antibody Fragment
}

\author{
Nesrine Chakroun, ${ }^{\dagger, \ddagger}$ David Hilton, ${ }^{\dagger, \ddagger}$ Shahina S. Ahmad, ${ }^{\ddagger}$ Geoffrey W. Platt, ${ }^{\S}$ and Paul A. Dalby, ${ }^{*},+$ \\ ${ }^{\dagger}$ EPSRC Centre for Innovative Manufacturing in Emergent Macromolecular Therapies, Department of Biochemical Engineering, \\ University College London, London WC1H 0AH, U.K. \\ ${ }^{\ddagger}$ Department of Biochemical Engineering, University College London, London WC1H 0AH, U.K. \\ ${ }^{\S}$ Unchained Laboratories, Unit 706, Avenue E West, Thorp Arch Estate, Wetherby LS23 7EG, U.K.
}

Supporting Information

ABSTRACT: The analytical characterization of biopharmaceuticals is a fundamental step in the early stages of development and prediction of their behavior in bioprocesses. Protein aggregation in particular is a common issue as it affects all stages of product development. In the present work, we investigate the stability and the aggregation kinetics of A33Fab, a therapeutically relevant humanized antibody fragment at a wide range of $\mathrm{pH}$, ionic strength, and temperature. We show that the propensity of $\mathrm{A} 33 \mathrm{Fab}$ to aggregate under thermally accelerated conditions is $\mathrm{pH}$ and ionic-strength dependent with a stronger destabilizing effect of ionic strength at low $\mathrm{pH}$. In the absence of added salts, A33Fab molecules appear to be protected from aggregation due to electrostatic colloidal repulsion at low $\mathrm{pH}$. Analysis by transmission electron microscopy identified significantly different aggregate species formed at low and high $\mathrm{pH}$. The correlations between apparent midpoints of thermal transitions ( $T_{\mathrm{m} \text {,app }}$ values), or unfolded mole fractions, and aggregation rates are reported here to be significant only at the elevated incubation temperature of $65^{\circ} \mathrm{C}$, where aggregation from the unfolded state predominates. At all other conditions, particularly at $4-45^{\circ} \mathrm{C}$, aggregation of $\mathrm{A} 33 \mathrm{Fab}$ was predominantly from a native-like state, and the kinetics obeyed Arrhenius behavior. Despite this, the rank order of aggregation rates observed at $45{ }^{\circ} \mathrm{C}, 23$ and $4{ }^{\circ} \mathrm{C}$ still did not correlate well to each other, indicating that forced degradation at elevated temperatures was not a good screen for predicting behavior at low temperature.

KEYWORDS: antibody fragment, protein aggregation, aggregation kinetics, protein formulation

\section{INTRODUCTION}

Therapeutic proteins have become one of the fastest growing classes of approved biopharmaceutical products. While monoclonal antibodies (mAbs) have been used for almost three decades, novel classes of therapeutic antibodies, such as antigen-binding fragments (Fabs), single-chain variable fragments $(\mathrm{ScFv})$ and single-domain antibodies ( $\mathrm{sdAb})$, have recently yielded promising results in preclinical developments and clinical trials. ${ }^{1}$ For example, Fabs are now used in the treatment of a wide variety of diseases such as rheumatoid arthritis, multiple sclerosis, and thrombosis. ${ }^{2}$ High purity and stable formulations are key attributes to the development and the manufacturing of such molecules. The robustness of the formulations against external stress factors is crucial as therapeutic proteins are exposed to various types of stress such as temperature, $\mathrm{pH}$, salts, mechanical stress, surface interaction, and oxidation. ${ }^{3-5}$ Protein aggregation is a common issue faced during manufacturing as it affects all stages from the production to the final administration. Indeed, biotherapeutic aggregation not only reflects a loss of valuable product, but also more importantly can lower the potency and efficacy of the molecule as well as a higher risk of adverse immunogenicity. ${ }^{6-8}$ Therefore, the prediction or control of protein aggregation during the production and storage of a biotherapeutic drug is much needed. $6,9,10$

Efforts to address the challenge of predicting or controlling protein aggregation currently align to two converging approaches. The first aims at gaining a more detailed understanding of the molecular and kinetic mechanisms of protein aggregation, and the effects of external stresses, to enable the improved design of processing and formulation conditions that minimize the amount and size of aggregates in a final product. Lumry and Eyring ${ }^{11}$ first proposed a mechanistic model of protein aggregation in which reversible changes of the native structure were followed by irreversible aggregation: $N \Leftrightarrow$

Received: May 18, 2015

Revised: December 9, 2015

Accepted: December 21, 2015

Published: December 21, 2015 
$\mathrm{U} \rightarrow \mathrm{F}$. Since then, multiple models for protein aggregation have been proposed illustrating a number of distinct pathways that could be summarized in five general mechanisms: (1) the reversible association of the native monomer, (2) the aggregation of conformationally altered monomers, (3) the aggregation of chemically modified monomers, (4) nucleationcontrolled aggregation, and (5) surface-induced aggregation. $^{12,13}$ However, the relative roles and interplay of these mechanisms, during the formulated storage and biomanufacturing of therapeutic proteins, are not yet fully understood. Previously, changes in the mechanism of aggregate growth have been observed as the solution conditions are varied. ${ }^{14}$ Clearly then, many more studies are required to determine whether such behavior is general or whether the predominant mechanisms are in any way related to particular conditions, bioprocesses, protein families, or protein structures.

The second approach uses rapidly measurable properties of a protein or process as indicators for predicting the propensity to aggregate. For example, apparent conformational stability measurements such as $T_{\mathrm{m}, \mathrm{app}}$, or forced degradation tests at elevated temperature or agitation, are currently the most popular indicators used to design new proteins and their formulations for storage stability to aggregation. The influences of conformational stability and external stresses on protein aggregation have been studied extensively, though mostly focused on disease-related protein fibrillation ${ }^{13,15-18}$ or antibody aggregation, ${ }^{14,19-24}$ and the extent to which apparent conformational stability correlates to aggregation rates remains hotly debated. ${ }^{24-26}$ Proteins can fully or partially lose their native structure upon destabilization by temperature, pressure, chaotropes, or mutations, allowing the exposure of buried regions, which in turn leads to aggregation. ${ }^{13,27}$ Several methods have also attempted to predict the relative aggregation propensity or solubility from protein sequence, such as TANGO $^{28}$ PASTA, $^{29}$ and AGGRESCAN, ${ }^{30}$ or from native protein structure features such as positively charged surface patches, ${ }^{27,31,32}$ structural classification, ${ }^{32}$ and the packing density and polarity of buried interfaces. ${ }^{27}$ These methods agree that good predictions of aggregation propensity or solubility require structural information about the protein, particularly the properties and stabilities of localized surface features or substructures that would lead to aggregation from near-native forms. Notably, however, none of them has relied upon calculations of global conformational stability to unfolding, suggesting that the common use of $T_{\mathrm{m} \text {,app }}$-values for predicting the stability of therapeutic protein formulations to aggregation may be an oversimplification or perhaps relevant only when aggregation occurs from highly unfolded states.

Changes in the non-native aggregation mechanisms of an antistreptavidin IgG1 were recently determined over a wide range of $\mathrm{pH}$ values and $\mathrm{NaCl}$ under accelerated conditions. ${ }^{14}$ Aggregation rates were influenced mainly by conformational stability (unfolding) of at least the Fab regions, which outweighed electrostatic colloidal attractions, whereas the aggregate growth mechanism was affected by changes in electrostatic colloidal interactions. In another study, ${ }^{19}$ the ionic strength was reported to have relatively minor qualitative effects on IgG1 unfolding, while $\mathrm{pH}$ had large effects. Colloidal interactions between native monomeric antibodies were also shown to be sensitive to both $\mathrm{pH}$ and ionic strength and indicated that electrostatic interactions and nonuniform surface-charge distributions were important at near-neutral $\mathrm{pH}$. Meanwhile, Menzen et al. ${ }^{20}$ reported that repulsive net charges at low $\mathrm{pH}$ increased the colloidal stability of IgG1, although a reduction of the conformational stability was observed. However, at neutral conditions and in the presence of salt, IgG1 unfolding was followed by its the precipitation.

For an IgG2, non-native oligomers were found to be soluble at $\mathrm{pH} 5.5$ above $15{ }^{\circ} \mathrm{C}$ but converted reversibly to visible/ insoluble particles at lower temperatures. ${ }^{21}$ Lower $\mathrm{pH}$ values yielded only soluble aggregates, whereas higher $\mathrm{pH}$ values resulted in insoluble aggregates. A different human IgG2 antibody exhibited a $\mathrm{pH}$-dependent dimer formation under normal storage conditions $\left(4{ }^{\circ} \mathrm{C}\right.$ or $\left.29^{\circ} \mathrm{C}\right) .{ }^{22}$ However, an inversed $\mathrm{pH}$-dependence was discovered for high molecular weight aggregate formation at higher temperatures $\left(37^{\circ} \mathrm{C}\right)$. The different stability profiles exhibited at the various storage conditions resulted in nonlinearity of the Arrhenius kinetics for aggregation. For the $\mathrm{pH}$ - and temperature-dependent denaturation of a mouse IgG2, the Fab fragment was shown to be the least stable to heat treatment, whereas the $\mathrm{Fc}$ region was least stable to decreasing $\mathrm{pH}^{33}$ Below the first unfolding transition, aggregation was found to be dependent on protein unfolding, whereby aggregation rates increased with the rate of unfolding at higher temperatures. The structure of the aggregates formed also depended on the denaturation method.

Clearly, while some broad generalities are apparent, there is no robust consensus across different IgG isoforms in terms of the underlying aggregation mechanisms. Furthermore, the relative influence of the $\mathrm{Fab}$ fragment and its conformational stability within the IgGs has been examined very little. ${ }^{34,35} \mathrm{~A}$ recent study of the effects of $\mathrm{NaCl}$ and $\mathrm{pH}$ on conformational stability, aggregation propensity, and chemical stability of a Fab showed that increases in $\mathrm{NaCl}$ led to enhanced conformational stability and decreased aggregation rates. ${ }^{36}$ However, it is not yet known whether this is a general observation across all Fab molecules. It is also not clear whether the previously observed correlations between apparent conformational stability and aggregation rate for an isolated $\mathrm{Fab}$ and for one of the above IgGls hold true at all incubation temperatures. In contrast to full IgGs, data on Fab stability are relatively scarce, yet as they appear to strongly influence IgG aggregation, insights on Fab molecules will greatly aid in our understanding of their role within the aggregation of full IgGs.

In the present work, we investigated the stability and the aggregation kinetics of $\mathrm{A} 33 \mathrm{Fab}$, a therapeutically relevant humanized antibody fragment. ${ }^{37}$ We demonstrate that the commonly assumed, but recently debated, relationship between apparent conformational stability $\left(T_{\mathrm{m}, \mathrm{app}}\right)$ and aggregation rate $22,24-26,33,36,38$ is only significant for A $33 \mathrm{Fab}$ at incubation temperatures close to the $T_{\mathrm{m}, \mathrm{app}}$, where aggregation from the unfolded state predominates. We also determined the aggregation kinetics to obey Arrhenius behavior except where conditions lead to significant unfolding. Finally, in contrast to the previous study of Fab aggregation, ${ }^{36}$ we found that for A33Fab, increased ionic strength was conformationally destabilizing and increased the rate of aggregation at low $\mathrm{pH}$ values, demonstrating that as for IgGs, different sequences within a protein family can readily modify the relative influences of external factors.

\section{MATERIALS AND METHODS}

Site-Directed Mutagenesis. E. coli strain W3110 containing plasmid pTTOD A33 IGS2 was provided by UCB (Slough, $\mathrm{UK})$. The $\mathrm{A} 33 \mathrm{Fab}^{37}$ originally provided was mutated into A33Fab-C226S (referred to as A33Fab in this manuscript) to 
minimize the dimerization due to the presence of an unpaired cysteine at position 226 . The rational mutagenesis was carried out using the QuikChange XL site-directed mutagenesis kit (Stratagene, USA). In-house electro-competent W3110 cells were used for $\mathrm{A} 33 \mathrm{Fab}$ expression and production.

Pilot-Scale A33Fab Production. Starter cultures were first grown in $2 \mathrm{xPY}$ complex media containing $10 \mu \mathrm{g} \mathrm{mL}-1$ of tetracycline at $37{ }^{\circ} \mathrm{C}, 200 \mathrm{rpm}$ for $4 \mathrm{~h}$ then transferred into SM6G defined media ${ }^{39}$ containing $112 \mathrm{~g} \mathrm{~L}^{-1}$ of glycerol and 10 $\mu \mathrm{g} \mathrm{mL}^{-1}$ of tetracycline and incubated at $30^{\circ} \mathrm{C}$ for about $20 \mathrm{~h}$ at $200 \mathrm{rpm}$. Two liters of this inoculum was transferred into 18 $\mathrm{L}$ of SM6G defined media in the $30 \mathrm{~L}$ fermenter (BIOSTAT Cplus, Sartorius, Goettingen, Germany). The dissolved oxygen tension (DOT) was maintained at $30 \%$, and $\mathrm{pH}$ was maintained at 6.95 using $50 \%(\mathrm{w} / \mathrm{v})$ ammonia solution and $20 \%(\mathrm{v} / \mathrm{v}) \mathrm{H}_{2} \mathrm{SO}_{4}$ and temperature at $30{ }^{\circ} \mathrm{C}$. After $32 \mathrm{~h}$, the temperature was reduced to $25^{\circ} \mathrm{C}$. Glycerol feeds, $\mathrm{Mg}^{2+}$, and $\mathrm{PO}_{4}{ }^{2-}$ were added to the culture at certain intervals. After approximately $36 \mathrm{~h}$, the production of $\mathrm{A} 33 \mathrm{Fab}$ was induced by the addition of $40 \mathrm{mM}$ of IPTG. The culture was harvested 36 $\mathrm{h}$ after induction and cells recovered using a Carr Powerfuge P6 centrifuge (Carr Centritech Separation Systems, Clearwater, FL, USA) and stored at $-80{ }^{\circ} \mathrm{C}$.

A33Fab Extraction and Purification. Cells were resuspended in $100 \mathrm{mM}$ Tris/10 mM EDTA solution, $\mathrm{pH}$ 7.4 and incubated overnight at $60{ }^{\circ} \mathrm{C}$ at $150 \mathrm{rpm}$. A centrifugation step (1h30, $13000 \mathrm{rpm})$ followed, and the A33Fab-rich supernatant was collected for purification. A33Fab was purified using the AKTA purifier FPLC system. Sepharose fast flow protein $G$ resin (GE healthcare) was packed in an XK16 column and equilibrated with $25 \mathrm{mM}$ sodium phosphate, $\mathrm{pH}$ 7.4. The filtered heat lysate was passed through the column, and the elution was carried out with $60 \mathrm{mM}$ sodium citrate, $\mathrm{pH}$ 3.4. An additional gel filtration step (HiLoad Superdex, GE Healthcare) was done in PBS, $\mathrm{pH} 7.4$ to ensure high purity of the protein as a monomer as shown in SI1.

Sample Preparation. The purified A33Fab was dialyzed overnight at $4{ }^{\circ} \mathrm{C}$ in ultrapure water using Dialysis Cassettes, 10K MWCO (Thermo Scientific) and its concentration adjusted to $2 \mathrm{mg} / \mathrm{mL}$. Prior to incubation, samples were diluted to a final concentration of $1 \mathrm{mg} / \mathrm{mL}$ with the desired buffer. Buffers used in this study included $20 \mathrm{mM}$ sodium citrate for $\mathrm{pH} 3.5,4.5$, and 5.5; $10 \mathrm{mM}$ sodium phosphate for $\mathrm{pH} \mathrm{7}$; and $20 \mathrm{mM}$ Tris for $\mathrm{pH} 8$ and $\mathrm{pH} 9$, ensuring an equivalent maximum contribution to ionic strength from each buffer of $20 \mathrm{mM}$. Sodium chloride was included to give final ionic strengths for buffer and salt combined, ranging between 20 and $500 \mathrm{mM}$. The lower ionic strength of $7 \mathrm{mM}$ at $\mathrm{pH} 3.5$ was achieved using $7 \mathrm{mM}$ sodium citrate. The lower ionic strengths of $5 \mathrm{mM}$ at $\mathrm{pH} 8$ and $1 \mathrm{mM}$ at $\mathrm{pH} 9$ were achieved using $10 \mathrm{mM}$ Tris.

Thermal Stability Studies. The midpoints of thermal transitions $\left(T_{\mathrm{m}, \mathrm{app}}\right)$ of $\mathrm{A} 33 \mathrm{Fab}$ in various formulations were determined by monitoring the intrinsic fluorescence using the Optim1000 (Unchained Laboratories, Wetherby, UK) with samples ramp-heated from 20 to $90{ }^{\circ} \mathrm{C}\left(1{ }^{\circ} \mathrm{C} / \mathrm{min}\right.$, including $30 \mathrm{~s}$ for measurement at each temperature). A typical fluorescence intensity curve and associated emission wavelength scans are shown in SI2. The ratio of the fluorescence intensity emission at 350 and $330 \mathrm{~nm}$ as a function of temperature was used to determine the $T_{\mathrm{m} \text {,app }}$ for the transition between the folded and the unfolded state by fitting the data to a two-state model ${ }^{40}$ using the following equation:

$$
I_{T}=\left(I_{\mathrm{N}}+a T\right)+\frac{\left(I_{\mathrm{D}}+b T-I_{\mathrm{N}}+a T\right)}{1+\exp \left[T_{\mathrm{m}, \mathrm{app}}-T / m\right]}
$$

where $I_{T}$ is the observed signal, $I_{\mathrm{N}}$ and $I_{\mathrm{D}}$ are the native and denatured baseline intercepts, $a$ and $b$ are the native and denatured baseline slopes, $T$ is the temperature, and $T_{\mathrm{m} \text {,app }}$ is the midpoint of the thermal transition. A two-state fit was used as this gave the simplest fit to the data. It is assumed that a rapid pre-equilibrium for protein unfolding exists prior to a relatively slow aggregation step. Thus, the aggregation rate increases with temperature and only approaches the time scale of the thermal ramping experiment as the temperature approaches the $T_{\mathrm{m}}$, where the protein becomes significantly unfolded. Therefore, $T_{\mathrm{m} \text {,app }}$ is closely linked to $T_{\mathrm{m}}$ but is also convoluted with a term that depends on the aggregation rate and experimental thermal ramping rate.

The apparent mole-fraction, $f_{\text {app}}$, of unfolded protein was calculated at relevant temperatures from

$$
f_{\text {app }}=\left(I_{T}-I_{\mathrm{D}}-b T\right) /\left(I_{\mathrm{N}}+a T-I_{\mathrm{D}}-b T\right)
$$

The onset aggregation temperature $\left(T_{\text {agg }}\right)$ was also determined as the point at which $10 \%$ increase in the light scattering at $266 \mathrm{~nm}$ occurs relative to the low-temperature baseline. All measurements were repeated at least three times.

Circular Dichroism. The UV and CD absorption spectra of A33Fab were acquired on an Applied Photophysics Chirascan Plus spectropolarimeter (Leatherhead, UK). The $1.0 \mathrm{~mm}$ and $0.5 \mathrm{~mm}$ Suprasil rectangular cells (Hellma UK Ltd.) were used in the region 400-190 $\mathrm{nm}$, and the following parameters were employed: $2 \mathrm{~nm}$ spectral bandwidth, $1 \mathrm{~nm}$ step size, and $1 \mathrm{~s}$ instrument time per point. UV and CD absorption spectra were buffer baseline corrected. Protein concentration was then calculated based upon the $A_{280}$ and the Beer-Lambert law. The far-UV CD spectra were corrected for concentration and path length and expressed in terms of $\Delta \varepsilon\left(\mathrm{M}^{-1} \mathrm{~cm}^{-1}\right)$ per amino acid residue $(\mathrm{MW}=113)$. Protein secondary structure contents were assessed using the Principle Component Regression method based upon 16 known protein structures ${ }^{41}$ embedded in the PLSPlus/IQ routine on GRAM32 AI software. For the thermal stability, the far-UV CD spectra of A33Fab were first recorded at room temperature $\left(20^{\circ} \mathrm{C}\right)$, cooled to $6{ }^{\circ} \mathrm{C}$, then heated to high temperature $\left(90^{\circ} \mathrm{C}\right)$ and recooled to $20^{\circ} \mathrm{C}$ after heating. The multiwavelength melting profiles, monitored at $\lambda$ (260-190 nm), were recorded during the heating process. The instrument was equipped with a Quantum NorthWest TC125 Peltier unit set to change temperature from 6 to $90{ }^{\circ} \mathrm{C}$ at $1{ }^{\circ} \mathrm{C}$ per minute rate with a $2{ }^{\circ} \mathrm{C}$ step size. Thus, after $20 \mathrm{~s}$ of temperature ramping by $2{ }^{\circ} \mathrm{C}$, the wavelength scan takes $100 \mathrm{~s}$ to complete using $1.42 \mathrm{~s}$ time-per-point $\mathrm{CD}$ measurement time and $1 \mathrm{~nm}$ step-size for $260-190 \mathrm{~nm}$, with a $2 \mathrm{~nm}$ Spectral Bandwidth. A $0.5 \mathrm{~mm}$ path length rectangular cell was employed. The temperature was measured directly with a thermocouple probe in the sample solution. Melting temperatures were fitted using a Levenberg-Marquardt algorithm (LMA) on the van't Hoff isochore. ${ }^{42}$

Aggregation Kinetics. The samples were incubated at 4 ${ }^{\circ} \mathrm{C}, 23{ }^{\circ} \mathrm{C}, 45^{\circ} \mathrm{C}$, and $65^{\circ} \mathrm{C}$ in glass vials with appropriate solid caps to minimize evaporation. Aliquots were taken at regular intervals, and the aggregation was quenched by placing the samples in ice and followed by centrifugation at $13000 \mathrm{rpm}$ for $45 \mathrm{~min}$ to remove any insoluble aggregates. A33Fab monomer loss was monitored by SEC-HPLC using a Zorbax-GF250 
A

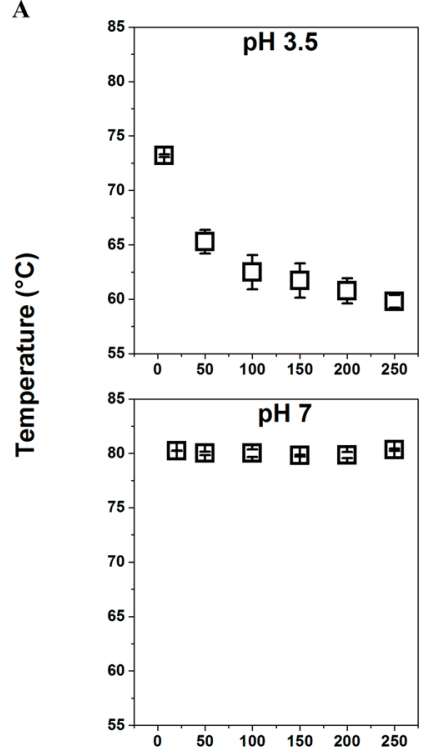

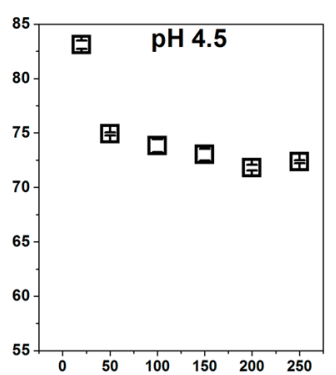

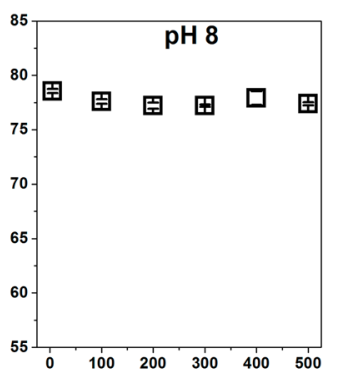

IS (mM)
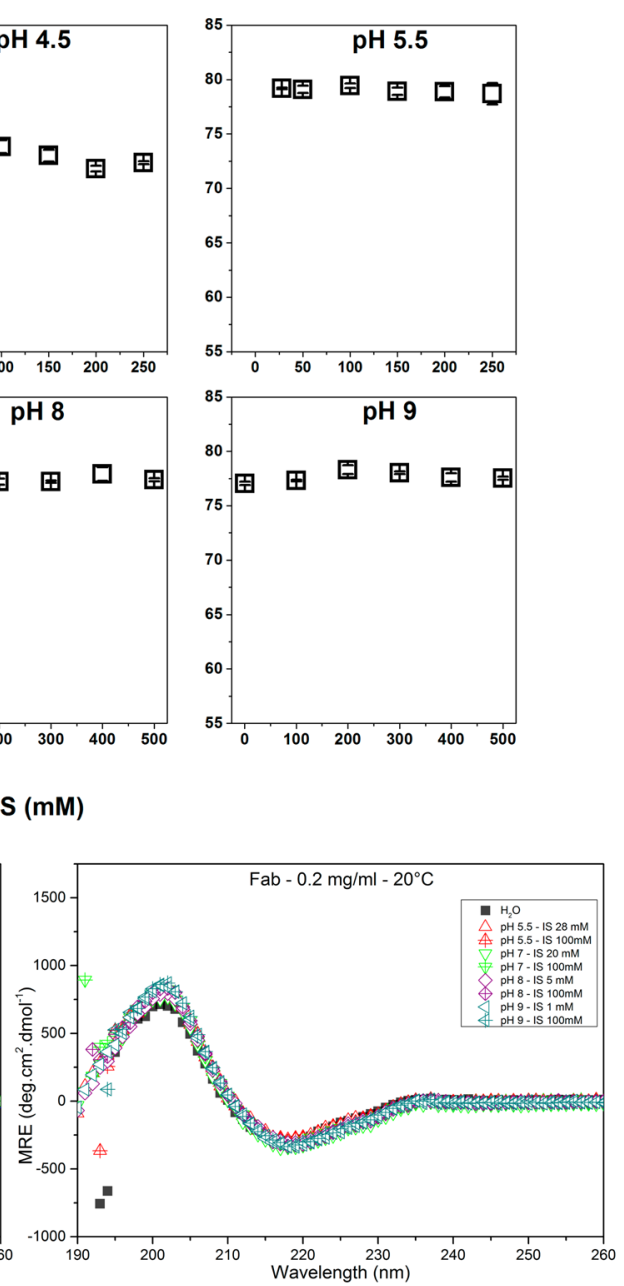

C
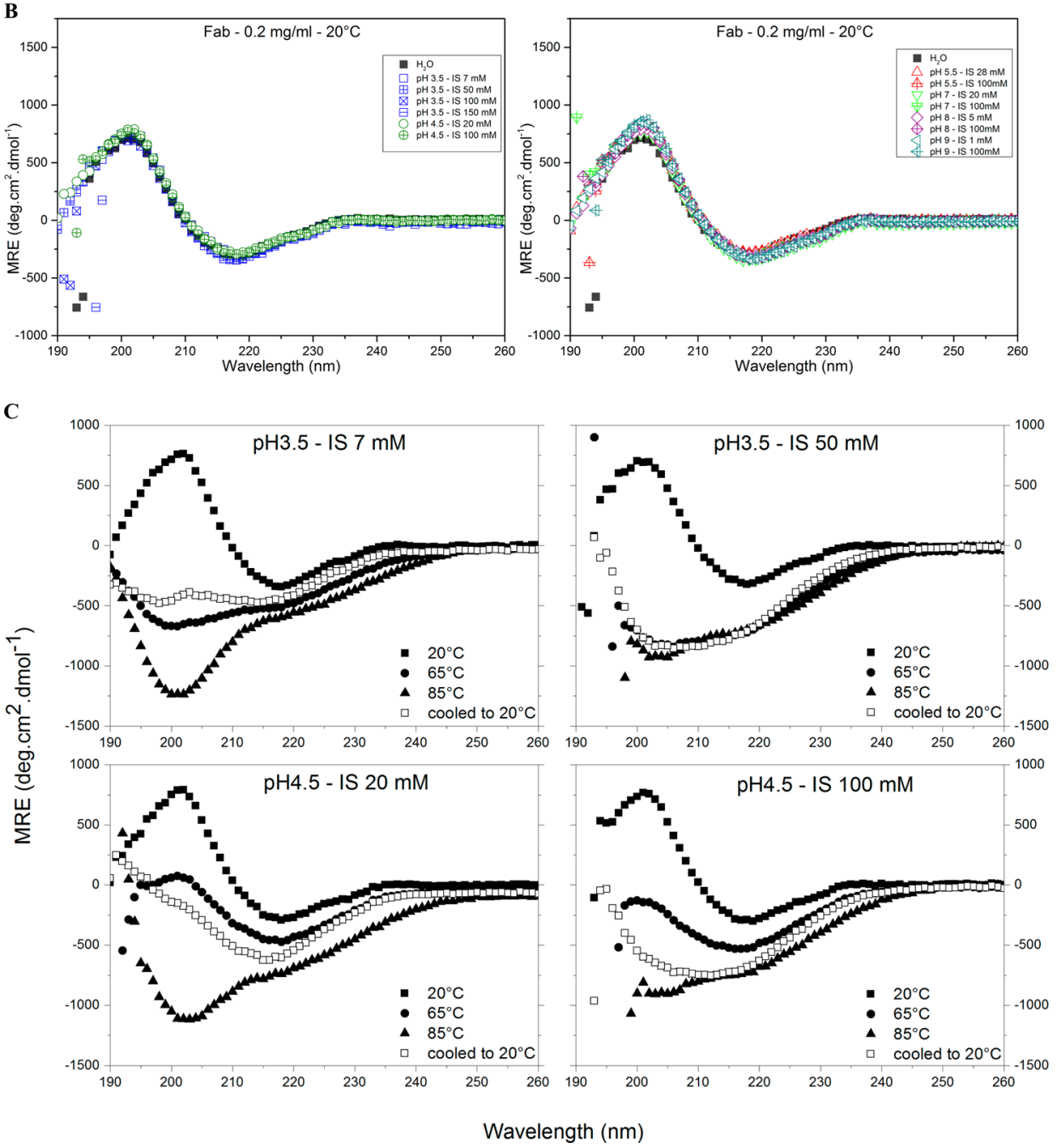

Figure 1. A33Fab thermal stability. (A) Midpoints of thermal transitions determined by intrinsic fluorescence at pH 3.5 to $\mathrm{pH} 9$, ionic strength (IS) 0-500 mM, at $1 \mathrm{mg} / \mathrm{mL}$ A33 Fab. Error bars are shown. (B) CD spectra of A33Fab at $0.2 \mathrm{mg} / \mathrm{mL}$ collected at $20{ }^{\circ} \mathrm{C}$ at pH 3.5 to $\mathrm{pH} 4.5$ (left) and $\mathrm{pH} 5.5$ to $\mathrm{pH} 9$ (right). (C) $\mathrm{CD}$ melting spectra at $20^{\circ} \mathrm{C}, 65^{\circ} \mathrm{C}, 85^{\circ} \mathrm{C}$, and after cooling back to $20{ }^{\circ} \mathrm{C}$, at $0.2 \mathrm{mg} / \mathrm{mL} \mathrm{A} 33 \mathrm{Fab}$. 
column and a 1200 HPLC Agilent system. Sodium phosphate, $200 \mathrm{mM}, \mathrm{pH} 7$ was used as a mobile phase. The elution profile was observed at an absorbance of 220 and $280 \mathrm{~nm}$. Peak areas were calculated by manual integration. Initial rates of aggregation $(v)$ were determined directly from a linear fit of the time-dependent peak-area data to the first $20 \%$ of monomer loss. All experiments were carried out in triplicate.

ThT Kinetics Assays. ThioflavinT (ThT) fluorescence in the presence of $\mathrm{A} 33 \mathrm{Fab}$ was obtained during isothermal incubation with an Optim445 (Unchained Laboratories, Wetherby, UK). ThT (Sigma, UK) was used at a final concentration of $50 \mu \mathrm{M}$, excited at $445 \mathrm{~nm}$, and the fluorescence signal recorded at $490 \mathrm{~nm}$. All kinetic measurements were carried out in a final volume of $9 \mu \mathrm{L}$ in triplicates with a final A33Fab concentration of $1 \mathrm{mg} / \mathrm{mL}$.

Static Light Scattering and Intrinsic Fluorescence. The light scattering signal intensity at $266 \mathrm{~nm}$ of Fab samples was collected simultaneously during both the ThT fluorescence experiments on the Optim 445 and the intrinsic fluorescence measurements on the Optim1000 (Unchained Laboratories, Wetherby, UK). All kinetic measurements were carried out in a final volume of $9 \mu \mathrm{L}$ in triplicates with a final A33Fab concentration of $1 \mathrm{mg} / \mathrm{mL}$. Fluorescence intensity kinetics of unfolding at $\mathrm{pH} 3.5$ was fit to a single exponential equation after the initial change due to thermal equilibration on the instrument and sample.

Isoelectric Point Prediction. The homology model for A33Fab was constructed from the humanized anti-IFN-gamma Fab crystal structure PDB $1 \mathrm{~T}^{2} \mathrm{~F}^{43}$ using SWISS MODEL software. ${ }^{44}$ The isoelectric point $(\mathrm{pI})$ was predicted using the online algorithm PROPKA 3.0 for protein only. ${ }^{45}$

Transmission Electron Microscopy (TEM). A33Fab samples were incubated at $65{ }^{\circ} \mathrm{C}, \mathrm{pH} 3.5$ and $\mathrm{pH} 9$, and each at ionic strengths of both $50 \mathrm{mM}$ and $150 \mathrm{mM}$. The samples were collected at various times of the kinetics for TEM observations. Approximately $2 \mu \mathrm{L}$ of freshly aggregated sample was placed dropwise onto carbon Formvar coated 400 mesh copper grids before partial air drying and blotting with filter paper. The grids were subsequently washed with ultrapure water before negative staining for $30 \mathrm{~s}$ with $0.2 \mu \mathrm{m}$ filtered uranyl acetate $(2 \% \mathrm{w} / \mathrm{v})$, blotting, and air-drying. Images were captured at room temperature using a JEOL-1010 transmission electron microscope (Tokyo, Japan), operating at $80 \mathrm{kV}$, equipped with a side-mounted Gatan Orius CCD digital camera.

\section{RESULTS AND DISCUSSION}

Apparent Conformational Thermal Stability. The apparent thermal conformational stability of A33Fab was investigated by simultaneously monitoring intrinsic fluorescence and static light scattering at $266 \mathrm{~nm}$, from which the thermal transition midpoint $\left(T_{\mathrm{m}, \mathrm{app}}\right)$ and the aggregation onset temperature $\left(T_{\mathrm{agg}}\right)$ were determined, respectively. As shown in Figure 1, panel A, $T_{\text {m,app }}$ values ranged between 59.7 and 83.1 ${ }^{\circ} \mathrm{C}$ consistent with apparent transition temperatures for other Fab proteins, as determined by CD, ${ }^{23,36} \mathrm{DSC}^{23,46-51} \mathrm{DSF}{ }^{51}$ and intrinsic fluorescence. ${ }^{51}$ An increased apparent conformational stability $\left(T_{\mathrm{m}, \mathrm{app}}>75^{\circ} \mathrm{C}\right)$ for $\mathrm{A} 33 \mathrm{Fab}$ was observed at $\mathrm{pH}$ values above $\mathrm{pH} 5$, where increasing the ionic strength with $\mathrm{NaCl}$ (up to $500 \mathrm{mM}$ ) had only minor effects on the $T_{\mathrm{m} \text {,app. }}$. This was in contrast to a destabilization by $\mathrm{NaCl}$ at low $\mathrm{pH}$, which resulted in $T_{\text {m,app }}$ values $<75{ }^{\circ} \mathrm{C}$. These data were generally consistent with previous reports for $\operatorname{IgG} 1 \mathrm{~s},{ }^{14}$ and also for a recombinant humanized Fab fragment, ${ }^{36}$ except that Wang et al. ${ }^{36}$ reported that the conformational stability of their $\mathrm{Fab}$ increased with salt concentration (from 0 to $2 \mathrm{M}$ ). It therefore appears that the specific effect of ionic strength on apparent conformational stability is Fab-dependent and not generalizable. Interestingly, low $\mathrm{pH}$ formulations in our study showed a significantly higher apparent conformational stability in the complete absence of added $\mathrm{NaCl}$, with a $T_{\text {m,app }}$ of 73.1 and $83.1^{\circ} \mathrm{C}$, at $\mathrm{pH} 3.5$ and $\mathrm{pH} 4.5$, respectively (Figure $1 \mathrm{~A}$ ). A similar overall trend was observed when monitoring the aggregation onset temperature $\left(T_{\mathrm{agg}}\right)$ by static light scattering at $266 \mathrm{~nm}$ (SI3), which also confirmed that all thermal melts induced rapid aggregation.

The secondary structure of $\mathrm{A} 33 \mathrm{Fab}$ was also monitored by circular dichroism (CD) as shown in Figure 1, panels B and C. $\mathrm{CD}$ spectra recorded immediately after equilibration into new buffers at $20{ }^{\circ} \mathrm{C}$ (Figure 1B) confirmed that all $\mathrm{pH}$ values and total ionic strength (IS) up to $100 \mathrm{mM}$ retained the same degree of structure and that this was consistent with the expected native Fab structure ( $36 \% \beta$-sheet content). ${ }^{36,52,53}$ The multiwavelength melting profiles recorded between 6 and $90{ }^{\circ} \mathrm{C}$ were used to monitor the changes of Fab secondary structure in various formulations (Figure $1 \mathrm{C}$ and SI4). The CD melting profiles at $220 \mathrm{~nm}$ (SI5A) gave CD $T_{\mathrm{m} \text {,app }}$-values that correlated well with the fluorescence-based $T_{\mathrm{m}, \mathrm{app}}$-values (SI5B), although CD $T_{\mathrm{m} \text {,app }}$-values were systematically underestimated. The CD spectra at high temperatures were complex and difficult to deconvolute into secondary structure components, while the magnitude of ellipticity at $220 \mathrm{~nm}$ also increased as the temperature increased. Simple denaturation to random coil would shift the ellipticity at $220 \mathrm{~nm}$ to zero; hence, the $\mathrm{CD}$ measurements at high temperature appear to have been affected by scatter from subvisible aggregates that lower the $T_{\mathrm{m}, \text { app }}$-values. Nevertheless, the $\mathrm{CD}$ data confirmed that the secondary structure of $\mathrm{A} 33 \mathrm{Fab}$ is more stable at $\mathrm{pH} 5-$ 7 , consistent with previous observations on a humanized Fab. ${ }^{36}$ In addition, the absorbance and high voltage (or dynode) values monitored at $220 \mathrm{~nm}$ (SI5A) increased significantly for $\mathrm{pH} 8$ and $\mathrm{pH} 9$ at $>70{ }^{\circ} \mathrm{C}$, indicating strong light scattering due to large particulate aggregation at these conditions. The samples were also observed to be highly turbid at the end of the melting experiments at $\mathrm{pH} \mathrm{8-9,} \mathrm{whereas} \mathrm{no} \mathrm{visible}$ aggregates were observed at the other conditions.

The CD spectra showed that A33Fab initially shifts to structure with increased $\beta$-sheet content (at $65^{\circ} \mathrm{C}$ ) and hence a stronger signal at $217 \mathrm{~nm}$, but also increased random coil, as observed from the more negative ellipticity at $200 \mathrm{~nm}$, and increased scattering due to aggregates as discussed above (Figure 1C, triangle symbols). The random coil content was greatest at low $\mathrm{pH}$ and $65{ }^{\circ} \mathrm{C}$, where the $T_{\text {m,app }}$ was exceeded and unfolding continued up to $85^{\circ} \mathrm{C}$. At $\mathrm{pH} 7-9$, the extent of random coil formation was generally less than at low $\mathrm{pH}$, although the CD signal was also likely to have been affected by phase separation to precipitates, observed visually at $\mathrm{pH} 8-9$. Recooling of samples from $85{ }^{\circ} \mathrm{C}$ back to $20{ }^{\circ} \mathrm{C}$ resulted in partial refolding at $\mathrm{pH}$ values 3.5-5.5 (Figure 1C, white symbols), particularly at low salt, but no refolding at $\mathrm{pH}$ 7-9 (SI4). This was consistent with the observed precipitation at the higher $\mathrm{pH}$. Interestingly, $\mathrm{Fab}$ partially refolded at $\mathrm{pH} 3.5$ only in the absence of added $\mathrm{NaCl}$ (Figure 1C, top panel). The partial refolding at low $\mathrm{pH}$ and the absence of visual precipitation are likely to have resulted from the increased electrostatic repulsion between proteins at low $\mathrm{pH}$. However, 

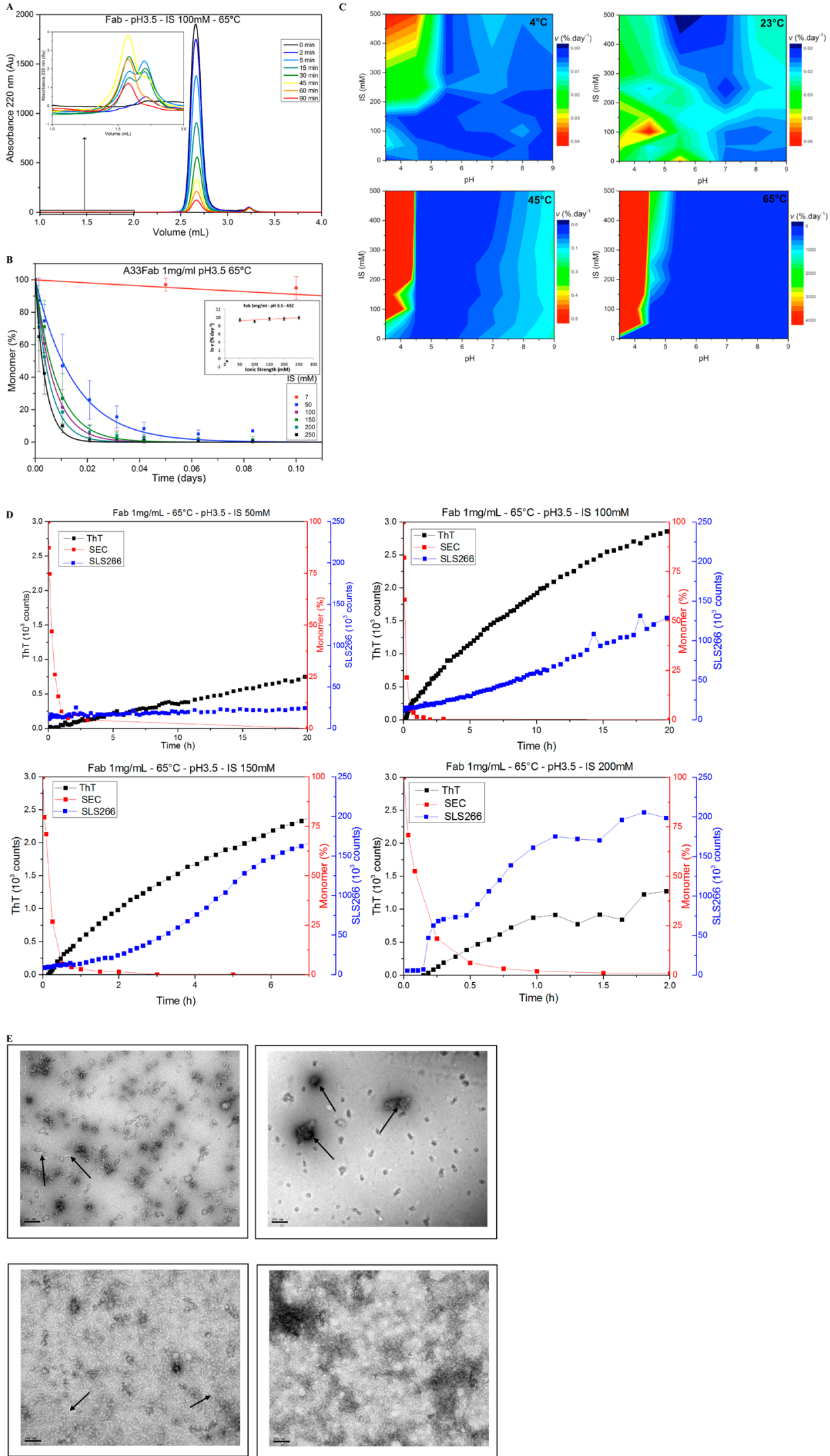

Figure 2. A33Fab aggregation kinetics. (A) Size exclusion chromatogram of A33Fab samples at $1 \mathrm{mg} / \mathrm{mL}$ at $\mathrm{pH} 3.5,100 \mathrm{mM}$ ionic strength from 2 to $90 \mathrm{~min}$. (B) Monomer peak area over time at pH 3.5, IS 0-250 mM (symbols), and corresponding single exponential fits (lines), (inset) linear correlation between the initial rate of monomer loss ( $v$ ) and IS. (C) Surface area plots of A33Fab monomer loss rates $(v)$ as a function of $\mathrm{pH}$ and IS determined from SEC-HPLC kinetics at $4{ }^{\circ} \mathrm{C}, 23{ }^{\circ} \mathrm{C}, 45^{\circ} \mathrm{C}$, and $65^{\circ} \mathrm{C}$. (D) Aggregation kinetics monitored by ThT fluorescence (black), static 
Figure 2. continued

light scattering $266 \mathrm{~nm}$ (blue), and SEC-HPC (red). (E) TEM of A33Fab incubated at $65{ }^{\circ} \mathrm{C}$ (top panel) until $20 \%$ monomer loss at pH 3.5 (left) and $\mathrm{pH} 9$ (right) at $50 \mathrm{mM}$ ionic strength. (Lower panel) TEM of A33Fab incubated $1 \mathrm{~h}$ (left) and $8 \mathrm{~h}$ (right) at $\mathrm{pH} 3.5,150 \mathrm{mM} \mathrm{IS.}$

partial refolding is retained at $100 \mathrm{mM}$ ionic strength for $\mathrm{pH} 4.5$ but not $\mathrm{pH} 3.5$, indicating that the decreased conformational stability at $\mathrm{pH} 3.5$ relative to that at $\mathrm{pH} 4.5$ is also a factor.

Overall, the thermal stability analyses show that the propensity of $\mathrm{A} 33 \mathrm{Fab}$ to aggregate under thermal denaturation is $\mathrm{pH}$ and ionic-strength dependent, with a stronger destabilizing effect of ionic strength at low $\mathrm{pH}$. In the absence of salts, A33Fab molecules appear to be colloidally protected from aggregation due to the strong electrostatic repulsions at low $\mathrm{pH}$. Additionally, there may be fewer intact salt bridges at low $\mathrm{pH}$ than at higher $\mathrm{pH}$, making the native conformation more susceptible to destabilization by salt.

Aggregation Kinetics. The kinetics of A33Fab monomer loss were obtained by SEC-HPLC over the same range of $\mathrm{pH}$ and ionic strength as described above, at $4{ }^{\circ} \mathrm{C}, 23{ }^{\circ} \mathrm{C}, 45{ }^{\circ} \mathrm{C}$, and $65{ }^{\circ} \mathrm{C}$. The A33Fab monomer eluted at $2.6 \mathrm{~mL}$ at a flowrate of $1 \mathrm{~mL} / \mathrm{min}$. The change in peak area was monitored in samples incubated in clinical grade stoppered-glass vials until fully degraded, otherwise for over 1 year at 4 and $23{ }^{\circ} \mathrm{C}$. Figure 2, panel A shows the A33Fab kinetics monitored by SECHPLC at $\mathrm{pH} 3.5,0$ to $250 \mathrm{mM}$ ionic strength, and $65^{\circ} \mathrm{C}$ as an illustrative example of the analysis carried out in this study. Extreme care was taken with the use of adequate screw caps to minimize evaporation. Evaporation was only observed after at least 6 months of storage, at $45^{\circ} \mathrm{C}$, and only then in occasional vials that were removed from the study.

The kinetic data were fitted linearly to obtain rates $(v)$ for the first $20 \%$ of A33Fab monomer loss. Typical decay curves are shown in Figure 2, panel $\mathrm{B}$ at $\mathrm{pH} 3.5,65^{\circ} \mathrm{C}$, and summarized for $4{ }^{\circ} \mathrm{C}, 23{ }^{\circ} \mathrm{C}, 45^{\circ} \mathrm{C}$, and $65{ }^{\circ} \mathrm{C}$ in Figure 2, panel $\mathrm{C}$. The minimum rate observable to $95 \%$ confidence by our analysis had $\ln (v) \leq-5.9\left(v\right.$ in $\%$ day $\left.^{-1}\right)$, which corresponded to approximately $1 \%$ monomer loss over 1 year. All data obtained at $23{ }^{\circ} \mathrm{C}, 45^{\circ} \mathrm{C}$, and $65^{\circ} \mathrm{C}$ were above this limit of detection, and only four out of 25 data points at $4{ }^{\circ} \mathrm{C}$ were at or below the limit of detection.

No lag-phase was observed for the rate of monomer loss under any of the conditions studied, indicating that monomer degradation was not accelerated at any point by the formation of a critical concentration of nuclei or other intermediate species. A linear correlation was observed between the rate of

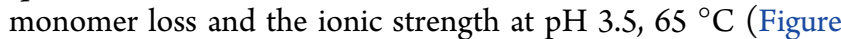
$2 \mathrm{~B}$, inset) and also at most other conditions explored in this study (SI6). This salt dependence was strongest at low $\mathrm{pH}$ ( $\mathrm{pH}$ 3.5 and $\mathrm{pH} 4.5$ ), in agreement with that observed for the thermal stability of A33Fab (Figure 1A). Also in agreement at $\mathrm{pH} 3.5$ and $\mathrm{pH} 4.5$ was the sharp deviation to $0 \mathrm{mM} \mathrm{NaCl}$ (7 $\mathrm{mM}$ and $20 \mathrm{mM}$ ionic strengths respectively), where the rate of monomer loss was considerably lower than expected, and the $T_{\mathrm{m}, \mathrm{app}}$ considerably higher than expected, from the respective linear dependencies at higher salt.

Figure 2, panel $\mathrm{C}$ summarizes the effects of $\mathrm{pH}$ and buffer ionic strength on $\mathrm{A} 33 \mathrm{Fab}$ rate of monomer loss for incubations at $4{ }^{\circ} \mathrm{C}, 23{ }^{\circ} \mathrm{C}, 45{ }^{\circ} \mathrm{C}$, and $65{ }^{\circ} \mathrm{C}$. Rates of monomer loss generally increased with temperature, as expected. ${ }^{24}$ Indeed, the half-life of $\mathrm{A} 33 \mathrm{Fab}$ was 5 years at $\mathrm{pH} 3.5,250 \mathrm{mM}$ ionic strength at $4{ }^{\circ} \mathrm{C}$, but only $2 \mathrm{~min}$ when incubated at $65{ }^{\circ} \mathrm{C}$. Figure 2, panel $\mathrm{C}$ also shows that low $\mathrm{pH}$ formulations $(\mathrm{pH} 3.5$ and $\mathrm{pH} 4.5)$ were more prone to aggregation at all temperatures, except in the absence of salts at high temperatures where strong electrostatic repulsions (calculated net charges of +41.8 and +27.7 at $\mathrm{pH} 3.5$ and $\mathrm{pH} 4.5$, respectively) appear to protect the Fab from aggregating. This is consistent with the salt dependence of $T_{\text {m,app }}$ in Figure 1, panel A, and both suggest that these electrostatic effects were screened out at $100 \mathrm{mM}$ ionic strength and above for $\mathrm{pH} 3.5$, and by only 50 $\mathrm{mM}$ and above for $\mathrm{pH}$ 4.5. These observations were also consistent with a previous study on IgG1 in which repulsive net charges at low $\mathrm{pH}$ increased the colloidal stability. ${ }^{20} \mathrm{~A} 33 \mathrm{Fab}$ exhibited the greatest stability to monomer loss at $\mathrm{pH} 5.5-7$, in agreement with the apparent conformational stability $\left(T_{\mathrm{m} \text {,app }}\right)$ reported above. The rate of $\mathrm{A} 33 \mathrm{Fab}$ monomer loss increased at above $\mathrm{pH} 7$ as the $\mathrm{pH}$ approached the isoelectric point ( $\mathrm{pI}$ 8.41). While broadly similar, the profiles at each temperature were not identical, suggesting that forced degradation kinetics at 45 or $65{ }^{\circ} \mathrm{C}$ does not accurately predict the same rank order of conditions that lead to the least aggregation at 23 or $4{ }^{\circ} \mathrm{C}$.

$\mathrm{A} 33 \mathrm{Fab}$ aggregation kinetics was also monitored using intrinsic fluorescence, ThioflavinT (ThT) fluorescence, and static light scattering at $266 \mathrm{~nm}$ (SLS266 nm) at $\mathrm{pH} 3.5,4.5$, and 9 , at $65{ }^{\circ} \mathrm{C}$, where the faster rates of aggregation and monomer loss were on time scales amenable to isothermal incubations and continual monitoring within the instrument itself. Intrinsic fluorescence intensity can be affected by tertiary structure unfolding as well as by the decrease in absorbable photons due to elastic light scattering by aggregates, and so this was also used to assess the rate of Fab unfolding or aggregation, as determined by the ratio of fluorescence intensities at 350 and $330 \mathrm{~nm} .{ }^{54}$ At $\mathrm{pH} 3.5,65^{\circ} \mathrm{C}$, the kinetics measured by intrinsic fluorescence for A33Fab (SI7) was biphasic. The fast phase occurred on the same time scale as monomer loss by SEC, consistent with rapid protein unfolding at these conditions. For the slower phase at $\mathrm{pH} 3.5,65^{\circ} \mathrm{C}$, the extent and rate of change of intrinsic fluorescence clearly increased with ionic strength, and the half-life ranged from $>10$ to $1 \mathrm{~h}$, for 50 and $200 \mathrm{mM}$ ionic strength, respectively. At $\mathrm{pH} 9$, the initial change in intrinsic fluorescence was not dependent on ionic strength, and the half-life was about $4 \mathrm{~h}$ at $65{ }^{\circ} \mathrm{C}$ and $10 \mathrm{~h}$ at $45{ }^{\circ} \mathrm{C}$, coincident with the monomer loss measured by SEC at $\mathrm{pH} 9.0$. By comparison, no significant change was observed at $\mathrm{pH} 3.5$ at $45^{\circ} \mathrm{C}$ or at $\mathrm{pH} 4.5$ over the first $40 \mathrm{~h}$ at $65^{\circ} \mathrm{C}$ or $120 \mathrm{~h}$ at 45 ${ }^{\circ} \mathrm{C}$ (SI7), indicating that the protein did not unfold under these conditions.

As shown in Figure 2, panel D, both ThT and SLS266 nm signals increased over time when $\mathrm{A} 33 \mathrm{Fab}$ was incubated at $\mathrm{pH}$ $3.5,65{ }^{\circ} \mathrm{C}$ in the presence of salts, suggesting the formation of larger $(>100 \mathrm{~nm})$ aggregates with increased intermolecular $\beta$ sheet structure. ${ }^{55}$ Previous studies have reported that ThT binds strongly to some IgG1 aggregates, ${ }^{14,19,56}$ but not for all IgG1 molecules. ${ }^{14,19,56}$ Increased ThT fluorescence can indicate binding to amyloid-like fibrils, or less ordered aggregates with increased intermolecular $\beta$-sheet structure, ${ }^{56}$ but can also potentially result from nonspecific binding to certain protein surface features formed by tyrosine residues. ${ }^{57}$ Either way, the contrasting behaviors of different aggregated antibodies suggest that there can be distinguishable differences within the structure 

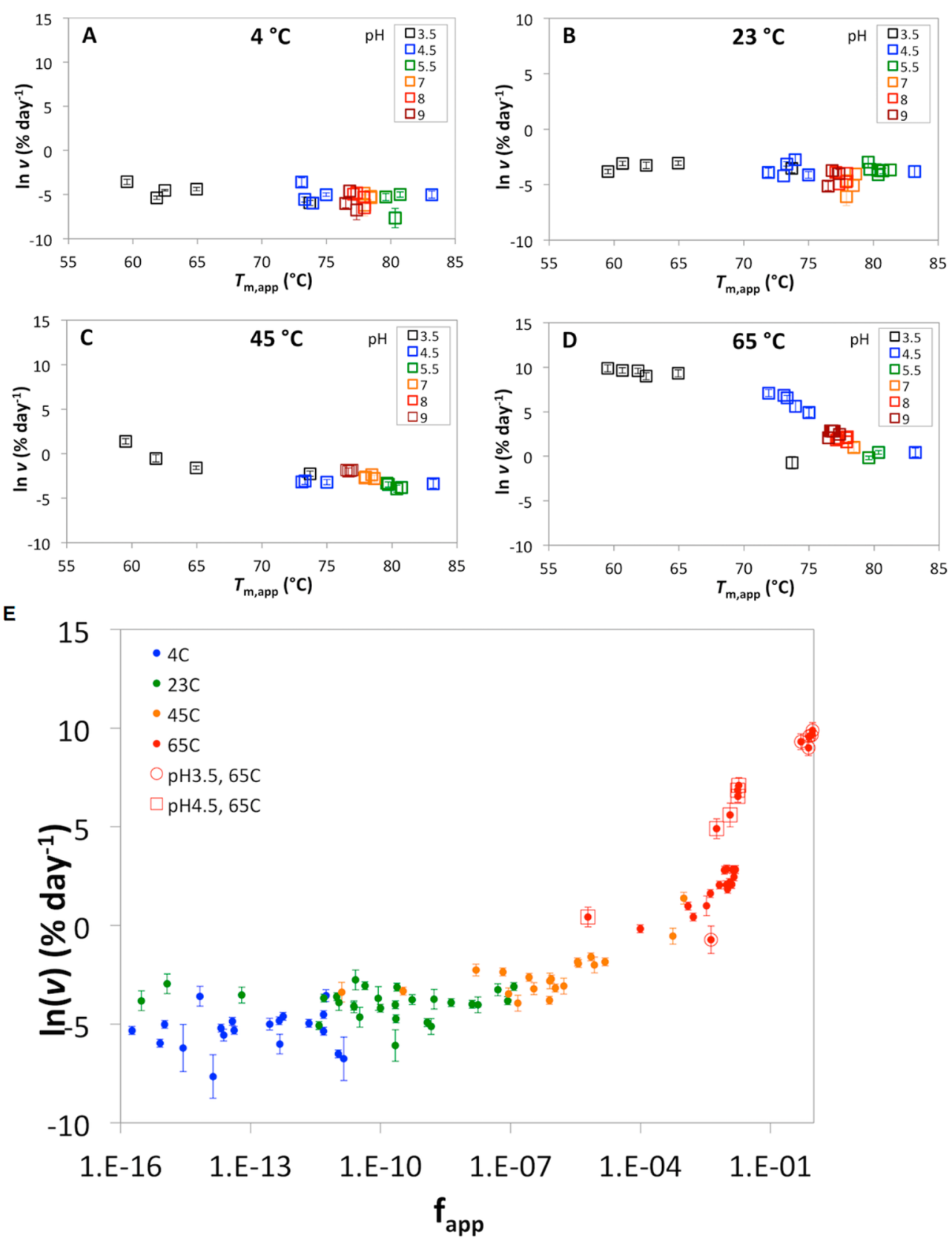

Figure 3. Correlation to the initial rates for monomer loss $\ln (v)$ and the midpoints of thermal transitions $\left(T_{\text {m,app }}\right)$ at $(\mathrm{A}) 4{ }^{\circ} \mathrm{C},(\mathrm{B}) 23^{\circ} \mathrm{C},(\mathrm{C}) 45^{\circ} \mathrm{C}$, and (D) $65^{\circ} \mathrm{C}$ and to $(\mathrm{E})$ the mole-fraction of unfolded protein $\left(f_{\text {app }}\right)$. Formulations range between $\mathrm{pH} 3.5$ and $\mathrm{pH} 9$, ionic strength from $1 \mathrm{mM}$ to $500 \mathrm{mM}$.

of IgG aggregates that may be either IgG or aggregation condition dependent.

The ThT signal showed no clear lag-phase, and the initial rate of ThT signal formation was significantly slower than though linearly proportional to the rate of monomer loss measured by SEC. It was also linearly proportional to and on the same time scale as the slow-phase rate of change observed by intrinsic fluorescence (SI8). This indicated that these events were directly linked such that the ThT signal increase, and the slow-phase intrinsic fluorescence change resulted from an aggregated state that forms more slowly than protein unfolding and the loss of native monomer. Overall, increasing $[\mathrm{NaCl}]$ at $\mathrm{pH} 3.5,65^{\circ} \mathrm{C}$ led to faster protein unfolding (measured by the intrinsic fluorescence fast-phase), faster monomer loss (measured by SEC), and then a more rapid formation of aggregates as measured by the slow-phase in intrinsic fluorescence and by ThT binding (Figure 2D).

It was also clear that the ThT signal increased prior to that of the static-light scattering, for which a lag-phase could be observed at $150 \mathrm{mM}$ and $200 \mathrm{mM}$ ionic strength. The lag phase observed by SLS at higher salt indicated that a second, larger aggregate population is formed either by nucleation onto or condensation of the intermediate aggregates, giving the ThT binding signal such that SLS detects only the subsequent larger aggregate. A low population of soluble oligomeric states was also observed by SEC-HPLC (Figure 2A, inset). The final ThT signal decreased as the ionic strength increased from $100 \mathrm{mM}$ to $200 \mathrm{mM}$, whereas the final SLS266 nm signal increased, which is consistent with either a final equilibrium between the ThT-fluorescent intermediate aggregate and the larger light- 

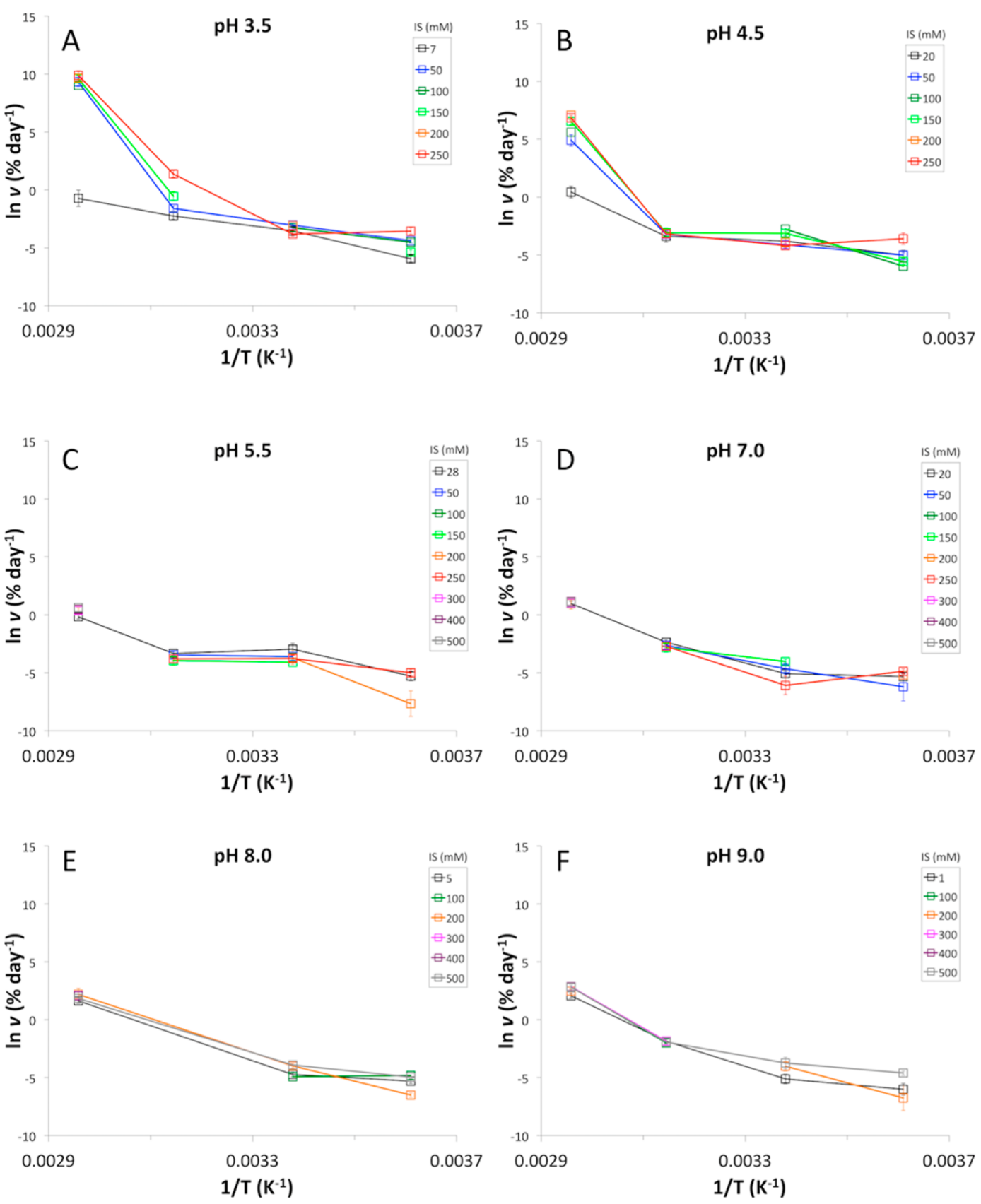

Figure 4. Arrhenius plots for A33Fab formulations from $\mathrm{pH} 3.5$ to $\mathrm{pH} 9$ and IS from $0 \mathrm{mM}$ to $500 \mathrm{mM}$.

scattering aggregates or a kinetic partitioning that is ionicstrength dependent.

ThT was also able to detect $\mathrm{A} 33 \mathrm{Fab}$ aggregation at $\mathrm{pH} 4.5$, $65{ }^{\circ} \mathrm{C}$ (SI9), whereas no increased fluorescence signal from ThT could be detected at $\mathrm{pH} 9.0,65^{\circ} \mathrm{C}$, possibly due to their rapid onward conversion, the formation of different aggregate forms, or to the hydroxylation of the ThT dye at basic $\mathrm{pH} .{ }^{58}$ As the monomer loss observed by SEC at $\mathrm{pH} 9.0$ occurs at the same time as both the increases in intrinsic fluorescence and SLS266 nm signals, with no observable ThT signal increase, the intermediate aggregate observed at $\mathrm{pH} 3.5,65{ }^{\circ} \mathrm{C}$ does not appear to populate at $\mathrm{pH} 9.0$, and the monomer appears to convert rapidly into large aggregates.

The morphology of A33Fab aggregates generated at $\mathrm{pH} 3.5$ and $\mathrm{pH} 9.0$, at $65^{\circ} \mathrm{C}$ were examined by TEM (Figure 2E). At $\mathrm{pH} 3.5$ after $20 \%$ monomer loss $\left(5 \mathrm{~min}\right.$ at $\left.65{ }^{\circ} \mathrm{C}\right)$, the aggregates appeared as elongated worm-like oligomers of about $10 \mathrm{~nm}$ width and up to $100 \mathrm{~nm}$ in length (Figure 2E, top left, arrows). These worm-like species were not observed directly by SEC, indicating that they are sufficiently large to be filtered out at the entrance to the column. They were also not sufficiently large $(100 \mathrm{~nm})$ to result in significant light scattering at 266 $\mathrm{nm}$. By contrast, the aggregates formed at $\mathrm{pH} 9$ after $20 \%$ monomer loss ( 11 days at $65{ }^{\circ} \mathrm{C}$ ) were bigger and more amorphous. When incubated for a longer time at $\mathrm{pH} 3.5$, the population of elongated oligomers increased concomitant with the ThT-signal increase (Figure 2E, lower left, arrows) and eventually resulted in their coalescence into larger aggregates, consistent with the increase in SLS266 nm signal (Figure 2E, lower right panel). It appears then that while these aggregates lacked any highly ordered fibrillar structural features, the ThT signal increase was linked to the formation of an elongated 
oligomer that was only partially ordered and perhaps contained some amyloid-like attributes. Similar "worm-like" semiflexible fibrils were reported for $\beta 2$-microglobulin and formed via a pathway distinct from that leading to the formation of amyloid fibrils under different solution conditions. ${ }^{59}$ Here, we also report two distinct aggregation pathways at low and high $\mathrm{pH}$ (at $65{ }^{\circ} \mathrm{C}$ ), whereby semiordered worm-like species that bind $\mathrm{ThT}$ form at low $\mathrm{pH}$ only, which then appear to either nucleate or condense into larger aggregates. Interestingly, the $\beta 2$ microglobulin worm-like fibrils were also reported to bind to ThT, and recent NMR data showed that they exhibit an ordered $\beta$-sheet core. ${ }^{60}$ By contrast, large amorphous aggregates formed at $\mathrm{pH} 9$ (at $65{ }^{\circ} \mathrm{C}$ ) with no observable binding to ThT.

Conformational Stability: A Predictor of Aggregation Kinetics? The stability and the aggregation propensities of A33Fab were monitored by intrinsic fluorescence $\left(T_{\mathrm{m}, \mathrm{app}}\right)$, static light scattering $\left(T_{\mathrm{agg}}\right)$, and SEC-HPLC $(v)$ at a wide range of $\mathrm{pH}$, ionic strength, and temperature as described above. To determine whether the apparent conformational stability of $\mathrm{A} 33 \mathrm{Fab}$ was correlated to the aggregation kinetics, the initial rates of monomer loss $(\ln v)$ were plotted as a function of $T_{\mathrm{m} \text {,app }}$ for all the formulations at each incubation temperature (Figure 3). A linear correlation was observed for the kinetics at $65{ }^{\circ} \mathrm{C}$, with an apparent kink within the $\mathrm{pH} 4.5$ conditions, separating the formulations containing $\mathrm{NaCl}$ at $\mathrm{pH} 3.5$ from the remaining conditions (Figure 3D). In the presence of $\mathrm{NaCl}$ at $\mathrm{pH} 3.5$, the incubation temperature of $65{ }^{\circ} \mathrm{C}$ was above the $T_{\mathrm{m}, \mathrm{app}}$, resulting in the irreversible unfolding of the protein as observed by CD (Figure 1C) and intrinsic fluorescence (SI7). Therefore, the distinct kink in the correlation was likely due to a shift toward aggregation from the unfolded state at $\mathrm{pH} 3.5$ and 50-250 $\mathrm{mM}$ ionic strength. Under these conditions (above the $\left.T_{\mathrm{m}, \mathrm{app}}\right)$, both native and unfolded states would be highly protonated $(+41.8$ for the native state at $\mathrm{pH} 3.5)$. Therefore, colloidal electrostatic repulsion between protein molecules would strongly increase and act to protect them from aggregation, contributing to the lower than expected $\ln v$ at $\mathrm{pH} 3.5,65^{\circ} \mathrm{C}$ and the kink in Figure 3, panel D. This is also in agreement with the work reported by Menzen et al. ${ }^{20}$ in which the repulsive net charge at low $\mathrm{pH}$ was shown to increase the colloidal stability of IgG1 even though a reduction of the conformational stability was also observed.

No kink was observed in the kinetics at $45{ }^{\circ} \mathrm{C}$ (Figure 3C), $23{ }^{\circ} \mathrm{C}$ (Figure 3B), or $4{ }^{\circ} \mathrm{C}$ (Figure 3A). The linear correlation between $\ln (v)$ and $T_{\mathrm{m} \text {,app }}$ was also present at $45^{\circ} \mathrm{C}$, though weaker than at $65{ }^{\circ} \mathrm{C}$. At 23 and $4{ }^{\circ} \mathrm{C}$, there was no longer an observable dependency of the rate of monomer loss on $T_{\mathrm{m} \text {,app }}$. A similar analysis was attempted between $T_{\text {agg }}$ and $t_{1 / 2}$, but no correlation could be found (data not shown). Overall, the $T_{\text {m,app }}$ of $\mathrm{A} 33 \mathrm{Fab}$ correlated with the rate of monomer loss, but only when the incubation temperature was close to the $T_{\text {m,app }}$. It is possible that there was a small correlation to $T_{\mathrm{m}, \text { app }}$ at low temperatures, but if any such correlation exists, it must be below the statistical resolution of our kinetic measurements.

To analyze the relative impact of protein unfolding, the apparent mole-fraction, $f_{\text {app}}$, of unfolded protein was estimated from the thermal melting profiles and compared to the initial rates of monomer loss (Figure 3E). A significant population of unfolded protein was observed only at $65{ }^{\circ} \mathrm{C}$, and then only at $\mathrm{pH} 8$ and 9 (0.4-1.5\% unfolded), and at $\mathrm{pH} 3.5$ and 4.5 $(>1.5 \%$ unfolded in the presence of $\mathrm{NaCl}$ ), consistent with the $\mathrm{CD}$ (Figure 1C) and intrinsic fluorescence (SI7). The profile obtained was sigmoidal, with a transition to a significantly faster rate of monomer loss at $\mathrm{pH} 3.5$ in the presence of $\mathrm{NaCl}$. This indicated aggregation from a structured state at low temperatures, with a shift in mechanism toward aggregation from the unfolded state in low $\mathrm{pH}$ at $65^{\circ} \mathrm{C}$. Partial unfolding to nativelike monomers, prior to protein aggregation, has been proposed $^{13}$ and reported previously for various proteins including $\mathrm{IgGs}^{61}$ amyloidogenic proteins such as prion ${ }^{15}$ and $\alpha$-synuclein ${ }^{96}$ and the SH3 domain. ${ }^{62}$ Future work will attempt to directly characterize whether such partially unfolded monomeric states influence the aggregation kinetics for A33Fab.

While an overall temperature dependence of $\ln v$ is evident in Figure 3, panel E, between the $4{ }^{\circ} \mathrm{C}, 23{ }^{\circ} \mathrm{C}$, and $65{ }^{\circ} \mathrm{C}$ conditions, the sensitivity of $\ln v$ to $f_{\text {app }}$, in these conditions is low, consistent with the observations for $T_{\mathrm{m} \text {,app }}$ in Figure 3, panels A-D. Such a loss of sensitivity to $T_{\mathrm{m} \text {,app }}$ or $f_{\text {app }}$, as the incubation temperature was decreased, suggests that the global conformational stability of the native state, which is measured relative to the unfolded state, is not a major contributing factor to the aggregation propensity under these conditions. The use of $T_{\text {m,app }}$ for formulation screening appeared to be limited in use for the case of $\mathrm{A} 33 \mathrm{Fab}$, ensuring that aggregation from the unfolded state was not significant. It did not appear to be a good indicator for rank ordering the ability of A33Fab formulations to minimize monomer loss during incubation at the lower temperatures, as relevant to biopharmaceutical storage.

Does Aggregation of Fab Follow Arrhenius Behavior? Arrhenius plots of $\ln (v)$ versus $1 / T$ at each $\mathrm{pH}$ (Figure 4 ) were found to be linear at all $\mathrm{pH}$, except under conditions where the protein was significantly unfolded, that is, for $\mathrm{pH} 3.5$ or 4.5 , at $65^{\circ} \mathrm{C}$, in the presence of $\mathrm{NaCl}$. The Arrhenius plots were also slightly curved at $\mathrm{pH} 9$ due to the higher rate at $65^{\circ} \mathrm{C}$, which likely results from the $0.8-1.5 \%$ mole-fraction of unfolded protein at these conditions. Similar non-Arrhenius observations have been reported previously for monoclonal IgG1 antibodies, ${ }^{63,64}$ where fitting of the data to modified Arrhenius equations enabled empirical models to be created that could be used to predict low temperature aggregation rates from high temperature data. Such behavior was also attributed to an increased population of the unfolded state.

While Arrhenius behavior was observed over the $4-45{ }^{\circ} \mathrm{C}$ range, comparison of the profiles of monomer loss rates in Figure 2, panel C, and a direct comparison in SI10, suggest that the rank order of conditions at $45{ }^{\circ} \mathrm{C}$ do not predict well those at $4{ }^{\circ} \mathrm{C}$. This could result from a complex dependence on $\mathrm{pH}$ and ionic strength for the slopes of the Arrhenius plots with A33Fab and cannot simply be accounted for by statistical errors in the data (SI10).

\section{SUMMARY}

Overall, our results suggest that the aggregation kinetics of A33Fab only appear to correlate strongly with conformational stability, as measured by $T_{\mathrm{m}, \mathrm{app}}$, at temperatures that approach the $T_{\text {m,app }} \cdot T_{\text {m,app }}$ was therefore not a strong indicator for predicting A33Fab aggregation rates at low temperatures. At elevated temperatures, protein aggregation from the unfolded state began to dominate as it became populated, whereas aggregation was from a structured monomeric state at lower temperatures and was not strongly dependent on the mole fraction of globally unfolded protein. Aggregation from the unfolded state at low $\mathrm{pH}$ and elevated temperatures led to the 
accumulation of soluble $100 \mathrm{~nm}$ worm-like aggregates and then larger insoluble aggregates by nucleation or aggregatecondensation. A kink in the correlation between rate of monomer loss at $65{ }^{\circ} \mathrm{C}$ and $T_{\text {m,app }}$ was due to low $\mathrm{pH}$ and high ionic strength conditions in which the protein began to unfold and also would have increased intermolecular electrostatic repulsion. Similarly complex mechanisms were observed previously for IgG1, ${ }^{63}$ and so simplifying the molecular system to Fab alone does not appear to reduce considerably the complexity of aggregation mechanisms. Arrhenius behavior was observed with A33Fab, except under low $\mathrm{pH}$ conditions at 65 ${ }^{\circ} \mathrm{C}$ where aggregation from the unfolded state predominated. However, the rank order of rates of monomer loss for the formulations at $45{ }^{\circ} \mathrm{C}$ did not predict those at $4{ }^{\circ} \mathrm{C}$, as the slopes of Arrhenius plots were also dependent on solution conditions. Instead, a robust and accurate extrapolation to rates at $4{ }^{\circ} \mathrm{C}$ would require rate measurements in every formulation across a wide range of temperatures.

\section{ASSOCIATED CONTENT}

\section{S Supporting Information}

The Supporting Information is available free of charge on the ACS Publications website at DOI: 10.1021/acs.molpharmaceut.5b00387.

SDS-PAGE gel of purified A33 Fab; intrinsic fluorescence intensity emission spectra of A33 Fab as a function of temperature; aggregation onset temperatures; $\mathrm{CD}$ melting spectra; $C D$ signal at $220 \mathrm{~nm}$, high voltage signal and absorbance, and CD $T_{\mathrm{m}}$-values compared to FLI $T_{\mathrm{m} \text {,app}}$-values; linear correlation between the initial rates of monomer loss $\ln (v)$ and ionic strength $(1-500 \mathrm{mM})$; time dependence of the ratio of intrinsic fluorescence intensity at 350 and $330 \mathrm{~nm}$; correlation plot between the initial rates by SEC-HPLC, ThT, and intrinsic fluorescence intensity; aggregation kinetics of Fab by ThT, SEC, and SLS; correlation between rates of monomer loss at 4 and $45{ }^{\circ} \mathrm{C}$ (PDF)

\section{AUTHOR INFORMATION}

\section{Corresponding Author}

*E-mail: p.dalby@ucl.ac.uk.

\section{Author Contributions}

The manuscript was written through contributions of all authors. All authors have given approval to the final version of the manuscript.

Notes

The authors declare no competing financial interest.

\section{ACKNOWLEDGMENTS}

The support of the Engineering and Physical Sciences Research Council (EPSRC) Centre for Innovative Manufacturing in Emergent Macromolecular Therapies (EP/I033270/1) is gratefully acknowledged. The Centre is part of the Advanced Centre for Biochemical Engineering, Department of Biochemical Engineering, University College London.

\section{REFERENCES}

(1) Nelson, A. L. Antibody fragments: hope and hype. mAbs 2010, 2 (1), 77-83.

(2) Enever, C.; Batuwangala, T.; Plummer, C.; Sepp, A. Next generation immunotherapeutics-honing the magic bullet. Curr. Opin. Biotechnol. 2009, 20 (4), 405-11.
(3) Manning, M. C.; Chou, D. K.; Murphy, B. M.; Payne, R. W.; Katayama, D. S. Stability of protein pharmaceuticals: an update. Pharm. Res. 2010, 27 (4), 544-75.

(4) Wang, W.; Nema, S.; Teagarden, D. Protein aggregation pathways and influencing factors. Int. J. Pharm. 2010, 390 (2), 89-99.

(5) Hawe, A.; Wiggenhorn, M.; van de Weert, M.; Garbe, J. H.; Mahler, H. C.; Jiskoot, W. Forced degradation of therapeutic proteins. J. Pharm. Sci. 2012, 101 (3), 895-913.

(6) Frokjaer, S.; Otzen, D. E. Protein drug stability: a formulation challenge. Nat. Rev. Drug Discovery 2005, 4 (4), 298-306.

(7) Hermeling, S.; Crommelin, D. J.; Schellekens, H.; Jiskoot, W. Structure-immunogenicity relationships of therapeutic proteins. Pharm. Res. 2004, 21 (6), 897-903.

(8) Rosenberg, A. S. Effects of protein aggregates: an immunologic perspective. AAPS J. 2006, 8 (3), E501-7.

(9) Cromwell, M. E.; Hilario, E.; Jacobson, F. Protein aggregation and bioprocessing. AAPS J. 2006, 8 (3), E572-9.

(10) Oliva, A.; Farina, J. B.; Llabres, M. New trends in analysis of biopharmaceutical products. Curr. Pharm. Anal. 2007, 3 (4), 230-248.

(11) Lumry, R.; Eyring, H. Conformation Changes of Proteins. J. Phys. Chem. 1954, 58 (2), 110-120.

(12) Philo, J. S.; Arakawa, T. Mechanisms of protein aggregation. Curr. Pharm. Biotechnol. 2009, 10 (4), 348-51.

(13) Dobson, C. M. Protein folding and misfolding. Nature 2003, 426 (6968), 884-90.

(14) Kim, N.; Remmele, R. L., Jr.; Liu, D.; Razinkov, V. I.; Fernandez, E. J.; Roberts, C. J. Aggregation of anti-streptavidin immunoglobulin gamma-1 involves Fab unfolding and competing growth pathways mediated by $\mathrm{pH}$ and salt concentration. Biophys. Chem. 2013, 172, 2636.

(15) Colby, D. W.; Prusiner, S. B. Prions. Cold Spring Harbor Perspect. Biol. 2011, 3 (1), a006833.

(16) Uversky, V. N.; Li, J.; Fink, A. L. Evidence for a partially folded intermediate in alpha-synuclein fibril formation. J. Biol. Chem. 2001, 276 (14), 10737-44.

(17) Lansbury, P. T.; Lashuel, H. A. A century-old debate on protein aggregation and neurodegeneration enters the clinic. Nature 2006, 443 (7113), 774-9.

(18) Eisele, Y. S. From soluble abeta to progressive abeta aggregation: could prion-like templated misfolding play a role? Brain Pathol. 2013, 23 (3), 333-41.

(19) Sahin, E.; Grillo, A. O.; Perkins, M. D.; Roberts, C. J. Comparative Effects of $\mathrm{pH}$ and Ionic Strength on Protein-Protein Interactions, Unfolding, and Aggregation for IgG1 Antibodies. J. Pharm. Sci. 2010, 99 (12), 4830-4848.

(20) Menzen, T.; Friess, W. Temperature-ramped studies on the aggregation, unfolding, and interaction of a therapeutic monoclonal antibody. J. Pharm. Sci. 2014, 103 (2), 445-55.

(21) Sahin, E.; Weiss, W. F.; Kroetsch, A. M.; King, K. R.; Kessler, R. K.; Das, T. K.; Roberts, C. J. Aggregation and pH-Temperature Phase Behavior for Aggregates of an IgG2 Antibody. J. Pharm. Sci. 2012, 101 (5), 1678-1687.

(22) Perico, N.; Purtell, J.; Dillon, T. M.; Ricci, M. S. Conformational implications of an inversed $\mathrm{pH}$-dependent antibody aggregation. $J$. Pharm. Sci. 2009, 98 (9), 3031-42.

(23) Vermeer, A. W.; Norde, W.; van Amerongen, A. The unfolding/ denaturation of immunogammaglobulin of isotype $2 b$ and its $F(a b)$ and F(c) fragments. Biophys. J. 2000, 79 (4), 2150-4.

(24) Wang, W.; Roberts, C. J. Aggregation of Therapeutic Proteins; Wiley: Hoboken, NJ, 2010; p 486.

(25) Maddux, N. R.; Iyer, V.; Cheng, W.; Youssef, A. M.; Joshi, S. B.; Volkin, D. B.; Ralston, J. P.; Winter, G.; Middaugh, C. R. High throughput prediction of the long-term stability of pharmaceutical macromolecules from short-term multi-instrument spectroscopic data. J. Pharm. Sci. 2014, 103 (3), 828-39.

(26) Brissos, V.; Goncalves, N.; Melo, E. P.; Martins, L. O. Improving kinetic or thermodynamic stability of an azoreductase by directed evolution. PLoS One 2014, 9 (1), e87209. 
(27) Angarica, V. E.; Sancho, J. Protein dynamics governed by interfaces of high polarity and low packing density. PLoS One 2012, 7 (10), e48212.

(28) Fernandez-Escamilla, A. M.; Rousseau, F.; Schymkowitz, J.; Serrano, L. Prediction of sequence-dependent and mutational effects on the aggregation of peptides and proteins. Nat. Biotechnol. 2004, 22 (10), 1302-6.

(29) Trovato, A.; Seno, F.; Tosatto, S. C. The PASTA server for protein aggregation prediction. Protein Eng., Des. Sel. 2007, 20 (10), $521-3$.

(30) Conchillo-Sole, O.; de Groot, N. S.; Aviles, F. X.; Vendrell, J.; Daura, X.; Ventura, S. AGGRESCAN: a server for the prediction and evaluation of "hot spots" of aggregation in polypeptides. BMC Bioinf. 2007, 8, 65 .

(31) Chan, P.; Curtis, R. A.; Warwicker, J. Soluble expression of proteins correlates with a lack of positively-charged surface. Sci. Rep. 2013, 3, 3333.

(32) Niwa, T.; Ying, B. W.; Saito, K.; Jin, W.; Takada, S.; Ueda, T.; Taguchi, H. Bimodal protein solubility distribution revealed by an aggregation analysis of the entire ensemble of Escherichia coli proteins. Proc. Natl. Acad. Sci. U. S. A. 2009, 106 (11), 4201-6.

(33) Vermeer, A. W.; Norde, W. The thermal stability of immunoglobulin: unfolding and aggregation of a multi-domain protein. Biophys. J. 2000, 78 (1), 394-404.

(34) Wu, H. X.; Kroe-Barrett, R.; Singh, S.; Robinson, A. S.; Roberts, C. J. Competing aggregation pathways for monoclonal antibodies. FEBS Lett. 2014, 588 (6), 936-941.

(35) Roque, C.; Sheung, A.; Rahman, N.; Ausar, S. F. Effect of polyethylene glycol conjugation on conformational and colloidal stability of a monoclonal antibody antigen-binding fragment (Fab'). Mol. Pharmaceutics 2015, 12 (2), 562-575.

(36) Wang, T.; Kumru, O. S.; Yi, L.; Wang, Y. J.; Zhang, J.; Kim, J. H.; Joshi, S. B.; Middaugh, C. R.; Volkin, D. B. Effect of ionic strength and $\mathrm{pH}$ on the physical and chemical stability of a monoclonal antibody antigen-binding fragment. J. Pharm. Sci. 2013, 102 (8), 2520-37.

(37) Weir, N.; Athwal, D.; Brown, D.; Foulkes, R.; Kollias, G.; Nesbitt, A.; Popplewell, A.; Spitali, M.; Stephens, S. A new generation of high-affinity humanized PEGylated Fab fragment anti-tumor necrosis factor- $\alpha$ monoclonal antibodies. Therapy 2006, 3 (4), 535545.

(38) Brader, M. L.; Estey, T.; Bai, S. J.; Alston, R. W.; Lucas, K. K.; Lantz, S.; Landsman, P.; Maloney, K. M. Examination of thermal unfolding and aggregation profiles of a series of developable therapeutic monoclonal antibodies. Mol. Pharmaceutics 2015, 12 (4), $1005-1017$.

(39) Popplewell, A. G.; Sehdev, M.; Spitali, M.; Weir, A. N. Expression of antibody fragments by periplasmic secretion in Escherichia coli. Methods Mol. Biol. 2005, 308, 17-30.

(40) Nashine, V. C.; Kroetsch, A. M.; Sahin, E.; Zhou, R.; Adams, M. L. Orthogonal high-throughput thermal scanning method for rank ordering protein formulations. AAPS PharmSciTech 2013, 14 (4), 1360-6.

(41) Malik, K. M. Chemometric and Quantum Mechanical Methods for Analysing CD Spectra. Ph.D. Thesis, King's College London, 1997.

(42) Applied Photophysics Ltd. Global 3 - Global Analysis for T-ramp, 1.2; 2007-2012.

(43) Bourne, P. C.; Terzyan, S. S.; Cloud, G.; Landolfi, N. F.; Vasquez, M.; Edmundson, A. B. Three-dimensional structures of a humanized anti-IFN-gamma Fab (HuZAF) in two crystal forms. Acta Crystallogr., Sect. D: Biol. Crystallogr. 2004, 60, 1761-1769.

(44) Arnold, K.; Bordoli, L.; Kopp, J.; Schwede, T. The SWISSMODEL workspace: a web-based environment for protein structure homology modelling. Bioinformatics 2006, 22 (2), 195-201.

(45) Olsson, M. H. M.; Sondergaard, C. R.; Rostkowski, M.; Jensen, J. H. PROPKA3: Consistent Treatment of Internal and Surface Residues in Empirical pK(a) Predictions. J. Chem. Theory Comput. 2011, 7 (2), 525-537.
(46) Tischenko, V. M.; Zav'yalov, V. P.; Medgyesi, G. A.; Potekhin, S. A.; Privalov, P. L. A thermodynamic study of cooperative structures in rabbit immunoglobulin G. Eur. J. Biochem. 1982, 126 (3), 517-21.

(47) Buchner, J.; Renner, M.; Lilie, H.; Hinz, H. J.; Jaenicke, R.; Kiefhaber, T.; Rudolph, R. Alternatively folded states of an immunoglobulin. Biochemistry 1991, 30 (28), 6922-9.

(48) Ionescu, R. M.; Vlasak, J.; Price, C.; Kirchmeier, M. Contribution of variable domains to the stability of humanized IgG1 monoclonal antibodies. J. Pharm. Sci. 2008, 97 (4), 1414-26.

(49) Welfle, K.; Misselwitz, R.; Hausdorf, G.; Hohne, W.; Welfle, H. Conformation, $\mathrm{pH}$-induced conformational changes, and thermal unfolding of anti-p24 (HIV-1) monoclonal antibody CB4-1 and its Fab and Fc fragments. Biochim. Biophys. Acta, Protein Struct. Mol. Enzymol. 1999, 1431 (1), 120-31.

(50) Salinas, B. A.; Sathish, H. A.; Shah, A. U.; Carpenter, J. F.; Randolph, T. W. Buffer-dependent fragmentation of a humanized fulllength monoclonal antibody. J. Pharm. Sci. 2010, 99 (7), 2962-74.

(51) Schaefer, J. V.; Pluckthun, A. Transfer of engineered biophysical properties between different antibody formats and expression systems. Protein Eng., Des. Sel. 2012, 25 (10), 485-506.

(52) Noelken, M. E.; Nelson, C. A.; Buckley, C. E., 3rd; Tanford, C. Gross Conformation of Rabbit $7 \mathrm{~S}$ Gamma-Immunoglobulin and Its Papain-Cleaved Fragments. J. Biol. Chem. 1965, 240, 218-24.

(53) Poljak, R. J.; Amzel, L. M.; Avey, H. P.; Chen, B. L.; Phizackerley, R. P.; Saul, F. Three-dimensional structure of the Fab' fragment of a human immunoglobulin at 2,8-A resolution. Proc. Natl. Acad. Sci. U. S. A. 1973, 70 (12), 3305-10.

(54) Garidel, P.; Hegyi, M.; Bassarab, S.; Weichel, M. A rapid, sensitive and economical assessment of monoclonal antibody conformational stability by intrinsic tryptophan fluorescence spectroscopy. Biotechnol. J. 2008, 3 (9-10), 1201-11.

(55) Krebs, M. R.; Bromley, E. H.; Donald, A. M. The binding of thioflavin-T to amyloid fibrils: localisation and implications. J. Struct. Biol. 2005, 149 (1), 30-7.

(56) Kayser, V.; Chennamsetty, N.; Voynov, V.; Helk, B.; Trout, B. L. Conformational stability and aggregation of therapeutic monoclonal antibodies studied with ANS and Thioflavin T binding. $m A b s$ 2011, 3 (4), 408-11.

(57) Biancalana, M.; Makabe, K.; Koide, A.; Koide, S. Molecular mechanism of thioflavin- $\mathrm{T}$ binding to the surface of beta-rich peptide self-assemblies. J. Mol. Biol. 2009, 385 (4), 1052-63.

(58) Fodera, V.; Groenning, M.; Vetri, V.; Librizzi, F.; Spagnolo, S.; Cornett, C.; Olsen, L.; van de Weert, M.; Leone, M. Thioflavin T hydroxylation at basic $\mathrm{pH}$ and its effect on amyloid fibril detection. J. Phys. Chem. B 2008, 112 (47), 15174-81.

(59) Gosal, W. S.; Morten, I. J.; Hewitt, E. W.; Smith, D. A.; Thomson, N. H.; Radford, S. E. Competing pathways determine fibril morphology in the self-assembly of beta2-microglobulin into amyloid. J. Mol. Biol. 2005, 351 (4), 850-64.

(60) Debelouchina, G. T.; Platt, G. W.; Bayro, M. J.; Radford, S. E.; Griffin, R. G. Magic angle spinning NMR analysis of beta2microglobulin amyloid fibrils in two distinct morphologies. J. Am. Chem. Soc. 2010, 132 (30), 10414-23.

(61) Rowe, E. S.; Tanford, C. Equilibrium and kinetics of the denaturation of a homogeneous human immunoglobulin light chain. Biochemistry 1973, 12 (24), 4822-7.

(62) Zhuravlev, P. I.; Reddy, G.; Straub, J. E.; Thirumalai, D. Propensity to form amyloid fibrils is encoded as excitations in the free energy landscape of monomeric proteins. J. Mol. Biol. 2014, 426 (14), 2653-66.

(63) Kayser, V.; Chennamsetty, N.; Voynov, V.; Helk, B.; Forrer, K.; Trout, B. L. Evaluation of a non-Arrhenius model for therapeutic monoclonal antibody aggregation. J. Pharm. Sci. 2011, 100 (7), 252642.

(64) Brummitt, R. K.; Nesta, D. P.; Roberts, C. J. Predicting accelerated aggregation rates for monoclonal antibody formulations, and challenges for low-temperature predictions. J. Pharm. Sci. 2011, $100,4234$. 


\section{NOTE ADDED AFTER ASAP PUBLICATION}

This Article was published ASAP on January 4, 2016, with an error in equation 1. The corrected version was reposted on January 6, 2016. 